\title{
Response of the gullet to gastric reflux in patients with hiatus hernia and oesophagitis
}

\author{
D. A. K. W O O D W A R D 1 \\ Oesophageal Laboratory, Queen Elizabeth Hospital, Birmingham 15
}

\begin{abstract}
The variability of reflux symptoms in patients with hiatus hernia is well known, and a poor correlation between the symptoms of oesophagitis and appearances at oesophagoscopy has been noted.

A study has been made of the relationship between four variables. These are the acid reflux occurring in the oesophagus, the peristaltic clearance, the oesophagitis present and the symptoms from which the patients are suffering.

Symptoms were found only in patients with oesophageal $p \mathrm{H}$ levels below 4 . However, such acid levels could oocur in the absence of significant symptoms and there was a poor correlation between symptoms and various levels of $p \mathrm{H}$ below this.

Poor motor function in the oesophagus was associated with poor clearance of acid from it. Patients with poor clearance show a greater tendency to have oesophagitis, but, despite this correlation, in the group as a whole, there was no olear relationship between the results of the tests and the severity of symptoms.
\end{abstract}

Evidence from three sources suggests that the symptoms of gastro-oesophageal regurgitation in patients with hiatus hernia may be related to prolonged oesophageal contact with gastric contents after an episode of reflux, because of a sluggish response to the refluxed material. Donner, Silbiger, Hookman, and Hendrix (1966) showed that in patients with hiatus hernia and symptoms of oesophagitis, delayed clearance of acid barium was associated with abnormal peristaltic activity in the gullet. Booth, Kemmerer, and Skinner (1968) demonstrated that symptomatic hiatus hernia patients required more voluntary swallows to clear a bolus of hydrochloric acid from the oesophagus than did normals or patients with asymptomatic hiatus hernia. Olsen and Schlegel (1965) have shown that, in severe inflammatory oesophagitis, abnormal oesophageal motor function is demonstrable manometrically. Since emptying of the oesophagus must depend in part on oesophageal motility, patients with hiatus hernia have been studied with the object of demonstrating a correlation between the removal of refluxed acid from the gullet, the patients' symptoms, and oesophageal motor function.

\section{METHOD}

Thirty-three patients with a sliding hiatus hernia were studied. There were 14 men and 19 women with ages ${ }^{1}$ Present address: Walsgrave Hospital, Coventry, CV2 2DX between 38 and 81 years. Patients with radiological or endoscopic evidence of oesophageal stricture were excluded because it was felt that this condition might produce mechanical interference with the dynamics of acid reflux or clearance.

ASSESSMENT OF SYMPTOMS Although patients with oesophageal stricture were excluded, dysphagia occurred in a few patients with functional disturbance of the oesophagus. The severity of reflux symptoms was graded by giving a total score of 0 to 8 to each patient, calculated by adding the scones $(0,1$ or 2$)$ for the severity of heartburn after food and after postural activity, and of regurgitation after food and after postural activity.

OESOPHAGITIS The severity of oesophagitis was assessed visually at oesophagoscopy in 26 patients and graded as follows: 0, no oesophagitis ; A, mild oesophagitis, a reddening of the mucosa; or $\mathbf{B}$, marked oesophagitis, a red mucosa which bled easily on instrumentation (Tables I and II).

OESOPHAGEAL MOTILITY This was studied with the patient supine by pressure recordings from two polyvinyl open tipped catheters with openings $5 \mathrm{~cm}$. apart continuously perfused with water at the rate of $17 \mu \mathrm{l}$./sec. by a pump. For the purpose of the $p \mathrm{H}$ test the distance of the cardia from the nares was measured by recording the position of the lower oesophageal intrinsic sphincter, or by identifying the gastro-oesophageal mucosal junction with a third catheter monitoring transmucosal potential differen- 
ces. The motor function of the lower $15 \mathrm{~cm}$. of the oesophagus was studied by recording its response to voluntary swallows. Pressures produced were registered by externally situated pressure transducers, the output from which was amplified and fed to a multichannel recorder with an event marker operated manually, when the patient executed an order to swallow.

Tests of oesophageal motility were performed in 27 patients. Abnormal motor function of the body of the oesophagus was said to be present if (1) over $25 \%$ of the responses to voluntary swallows were nonperistaltic in nature ; $(2)$ repetitive non-peristaltic contractions occurred after swallows or spontaneously; or (3) there was evidence of motor failure with rises in oesophageal pressure in response to voluntary swallows remaining persistently below $20 \mathrm{~mm}$. $\mathrm{Hg}$.

OESOPHAGEAL ACIDITY Acidity in the gullet was monitored in all patients by placing a $p \mathrm{H}$ electrode (Cambridge, Intestinal) via the nares $5 \mathrm{~cm}$. above the cardia and recording $p \mathrm{H}$ continuously for a period of 15 hours after the evening meal. The patient lay supine with two pillows and no restriction to movement during sleep. Symptoms of gastro-oesophageal reflux were noted by the patient if they occurred during the test.

A 15-hour record of oesophageal $p \mathrm{H}$ was obtained for each patient and each record was analysed: (1) The total time for which the oesophageal $p \mathrm{H}$ was $<5,<4$, and $<3$ was measured and expressed as a percentage of the 15-hour period. (2) The $p \mathrm{H}$ trace was examined and the length of time measured for which oesophageal $p \mathrm{H}$ remained below basal levels after a drop of $2 \mathrm{pH}$ units or more (signifying a reflux episode). The number of such episodes was recorded in three groups, of short, medium and long duration, lasting $<15$ minutes, $15-45$ minutes and $>45$ minutes, respectively.

\section{RESULTS}

RELATION OF OESOPHAGEAL PH TO SYMPTOMS AND SEVERITY OF OESOPHAGITIS Tables I and II list the patients in the order of severity of acid reflux measured by the test. In nine (Table I), oesopha-

T A B L E I

REFLUX TO LESS THAN pH 5 AND GREATER THAN pH 4

\begin{tabular}{|c|c|c|c|c|c|c|}
\hline \multirow{2}{*}{ Patient } & \multirow{2}{*}{$\begin{array}{l}\text { Symptom } \\
\text { Score }\end{array}$} & \multicolumn{3}{|c|}{$p \mathrm{H} \%$ Time } & \multirow{2}{*}{$\begin{array}{l}\text { Oesopha- } \\
\text { goscopic } \\
\text { Findings }\end{array}$} & \multirow{2}{*}{$\begin{array}{l}\text { Oesopha- } \\
\text { geal } \\
\text { Motility }\end{array}$} \\
\hline & & $<5$ & $<4$ & $<3$ & & \\
\hline $\begin{array}{l}1 \\
2 \\
3 \\
4 \\
5 \\
6 \\
7 \\
8 \\
9\end{array}$ & $\begin{array}{l}2 \\
2 \\
1 \\
3 \\
4 \\
2 \\
3 \\
2 \\
2\end{array}$ & $\begin{array}{l}0 \cdot 1 \\
0 \cdot 3 \\
0 \cdot 6 \\
1 \\
1 \cdot 4 \\
2 \cdot 0 \\
2 \cdot 6 \\
7 \cdot 6 \\
9 \cdot 3\end{array}$ & $\begin{array}{l}\mathbf{0} \\
0 \\
0 \\
0 \\
0 \\
0 \\
0 \\
0 \\
0\end{array}$ & $\begin{array}{l}0 \\
0 \\
0 \\
0 \\
0 \\
0 \\
0 \\
0 \\
0\end{array}$ & $\begin{array}{l}\mathbf{0} \\
\mathbf{0} \\
\mathbf{0} \\
\mathbf{0} \\
\mathbf{B} \\
0 \\
\mathbf{0} \\
\mathbf{A}\end{array}$ & $\begin{array}{l}\text { Normal } \\
\text { Normal } \\
\text { Normal } \\
\text { Normal } \\
\text { Normal } \\
\text { Abnormal } \\
\text { - } \\
\text { Normal }\end{array}$ \\
\hline
\end{tabular}

T A B L E I I

REFLUX TO LESS THAN pH 4 OR 3

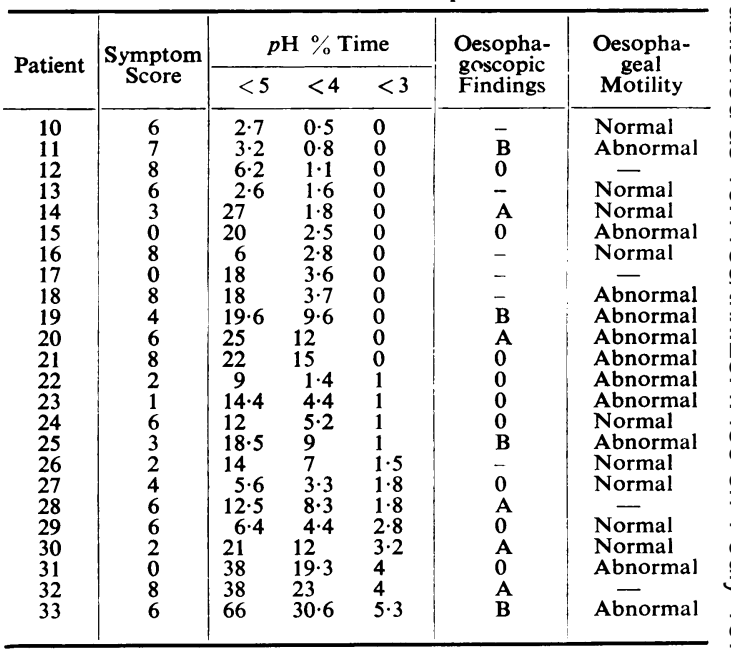

geal $p \mathrm{H}$ did not fall below 4 during the test for a measurable period. Before the test these patients suffered only minor symptoms of gastro-oesophageal reflux (symptom score 1 to 4 ). Seven of the nine patients had absent or minor oesophagitis and only one had marked oesophagitis. In this patient it was felt that narrowing of the oesophagus produced by oesophagitis may have been preventing reflux.

Twenty-four patients exhibited acid reflux to levels less than $p \mathrm{H} 4$, and 12 to less than $p \mathrm{H} 3$ (Table II). The symptoms of patients refluxing to below $p \mathrm{H} 3$ were no more severe than those refluxing only to below $p \mathrm{H} 4$. In fact the severity

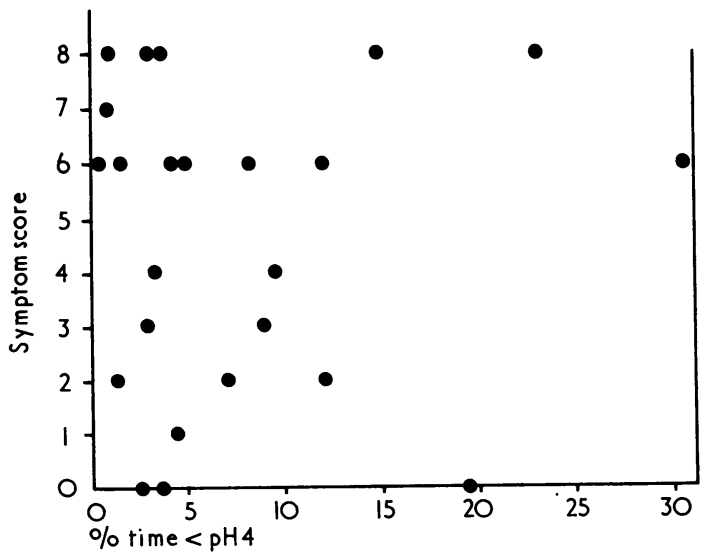

FIG. 1. There is not a constant relationship between the severity of symptoms and the degree of acid reflux to less than $\mathrm{pH} 4$. 
of reflux as assessed by the test showed a poor correlation with the severity of previously assessed symptoms of gastro-oesophageal reflux (Fig. 1). Similarly, severe reflux was not always associated with gross visual oesophagitis, one of the severest refluxers in the group (31) having no visual or histological oesophagitis.

OESOPHAGEAL MOTILITY AND SEVERITY OF REFLUX Of the 27 patients with motility studies, by the criteria defined 15 patients had normal and 12 abnormal oesphageal motility (Table III). Abnormal oesophageal motility was not associated with more severe symptoms of reflux though the three patients with dysphagia all occurred in this group.

\section{T A B L E II I}

\section{RESULTS OF OESOPHAGEAL MOTILITY TESTING}

\begin{tabular}{|c|c|c|c|c|c|c|}
\hline \multirow[b]{2}{*}{ Patient } & \multirow{2}{*}{$\begin{array}{c}\text { Pressure } \\
\text { in Lower } \\
\text { Oesopha- } \\
\text { geal } \\
\text { Sphincter } \\
\text { (mm. Hg) }\end{array}$} & \multicolumn{4}{|c|}{ Swallows } & \multirow[b]{2}{*}{$\underset{(\mathrm{mm} . \mathrm{Hg})}{\stackrel{\text { Max. }}{\text { Pressure }}}$} \\
\hline & & Total & $\begin{array}{c}\text { No } \\
\text { Res- } \\
\text { ponse }\end{array}$ & $\begin{array}{c}\text { Peri- } \\
\text { stal- } \\
\text { tic }\end{array}$ & $\begin{array}{l}\text { Non } \\
\text { Peri- } \\
\text { staj- } \\
\text { tic }\end{array}$ & \\
\hline $\begin{array}{c}\text { Normal } \\
1 \\
2 \\
3 \\
4 \\
5 \\
9 \\
10 \\
13 \\
14 \\
16 \\
24 \\
26 \\
27 \\
29 \\
30\end{array}$ & $\begin{array}{r}0 \\
4 \\
9 \\
11 \\
12 \\
7 \\
20 \\
6 \\
0 \\
3 \\
4 \\
18 \\
7 \\
2 \\
13\end{array}$ & $\begin{array}{l}15 \\
21 \\
33 \\
10 \\
21 \\
24 \\
15 \\
18 \\
25 \\
17 \\
18 \\
20 \\
20 \\
32 \\
13\end{array}$ & $\begin{array}{l}0 \\
3 \\
0 \\
0 \\
0 \\
0 \\
1 \\
2 \\
0 \\
0 \\
0 \\
0 \\
0 \\
5 \\
0\end{array}$ & $\begin{array}{l}12 \\
18 \\
33 \\
10 \\
16 \\
24 \\
11 \\
16 \\
25 \\
17 \\
14 \\
20 \\
15 \\
19 \\
13\end{array}$ & $\begin{array}{l}3 \\
0 \\
0 \\
0 \\
5 \\
0 \\
3 \\
0 \\
0 \\
0 \\
4 \\
0 \\
5 \\
8 \\
0\end{array}$ & $\begin{array}{l}50 \\
40 \\
40 \\
30 \\
35 \\
25 \\
60 \\
40 \\
40 \\
30 \\
40 \\
25 \\
45 \\
30 \\
40\end{array}$ \\
\hline
\end{tabular}

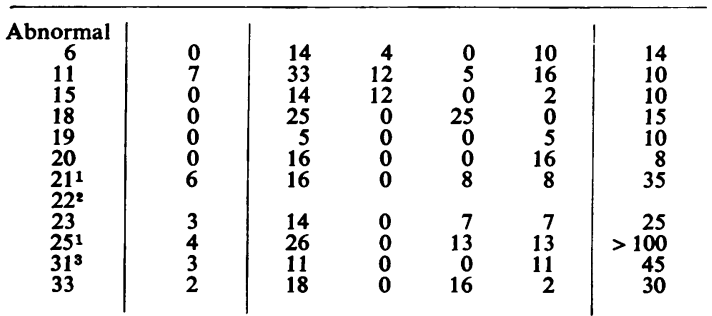

1 Also showed repetitive and spontaneous contractions suggestive of spasm.

Abnormal motility detected radiologically

Picture of diffuse spasm shown radiologically

As judged by the percentage time $\mathrm{pH}$ in the gullet was less than 5 or 4 , patients with abnormal motility were exposed to acid for longer than patients with normal motility, though the differences were not statistically significant (Table IV).

The mean sphincter strength was significantly greater in patients with normal motility than in those with abnormal motility. Nevertheless, the former gnoup were as prone to reflux episodes as the latter (Table IV).
T A B L E IV

SEVERITY OF REFLUX AND OESOPHAGEAL MOTILITY

\begin{tabular}{|c|c|c|c|c|}
\hline & & \multicolumn{2}{|c|}{ Oesophageal Motility } & \multirow{2}{*}{$\begin{array}{c}\text { Significance } \\
\text { of Difference }\end{array}$} \\
\hline & & Normal & Abnormal & \\
\hline No. of patients .. & .. & 15 & 12 & - \\
\hline 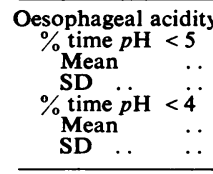 & $\begin{array}{l}\cdots \\
\cdots \\
\cdots \\
.\end{array}$ & \begin{tabular}{r|}
$10 \cdot 3$ \\
$13 \cdot 3$ \\
$4 \cdot 3$ \\
$3 \cdot 3$ \\
\end{tabular} & $\begin{array}{r}20 \cdot 1 \\
17 \cdot 1 \\
7 \cdot 8 \\
5 \cdot 9 \\
\end{array}$ & $\begin{array}{l}0.05<P<0.1 \\
0.05<P<0.1\end{array}$ \\
\hline 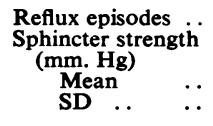 & $\because$ & $\begin{array}{l}171 \\
\\
7 \cdot 7 \\
5.9\end{array}$ & $\begin{array}{l}90 \\
\\
3 \cdot 3 \\
3 \cdot 9\end{array}$ & $\begin{array}{r}- \\
P<0.025 \\
(t \text { test })\end{array}$ \\
\hline
\end{tabular}

The patients with abnormal motility were exposed to acid for longer than patients with normal motility, though the differences are not statistically significant.

DURATION OF REFLUX EPISODES Table $\mathrm{V}$ relates oesophageal motor funotion to short, medium, or long duration reflux episodes in each patient. Short duration episodes, with oesophageal $p \mathrm{H}$ remaining low for periods lasting less than 15 minutes, occurred equally in patients with abnormal as in those with normal oesophageal

T A B L E V

DURATION OF REFLUX EPISODES AND OESOPHAGEAL

\begin{tabular}{|c|c|c|c|}
\hline & \multicolumn{2}{|c|}{ Oesophageal Motility } & \multirow{2}{*}{$\begin{array}{l}\text { Significance } \\
\text { of Difference }\end{array}$} \\
\hline & Normal & Abnormal & \\
\hline No. of patients ... & 15 & 12 & - \\
\hline $\begin{array}{c}\begin{array}{c}\text { No. of patients with } \\
\text { reflux episodes lasting } \\
<15 \mathrm{~min} \\
15-45 \mathrm{~min}\end{array} \\
>45 \mathrm{~min}\end{array}$ & $\begin{array}{r}15 \\
6 \\
1\end{array}$ & $\begin{array}{r}10 \\
9 \\
11\end{array}$ & $\begin{array}{l}\chi^{2} 2.042 \\
P>0.3 \\
\chi^{2} 16.217 \\
P<0.001\end{array}$ \\
\hline
\end{tabular}

Patients with abnormal motility showed a significant increase in prolonged reflux episodes.

motility. Slower clearance of acid in times of between 15 and 45 minutes occurred in a higher proportion of patients with abnormal than with normal oesophageal motility tests, though the difference was not significant. However, all but one of the 12 patients with abnormal motility demonstrated episodes when oesophageal $p \mathrm{H}$ remained low for longer than 45 minutes, whereas this occurred in only one of the 15 patients with normal motility, a statistically significant difference. 


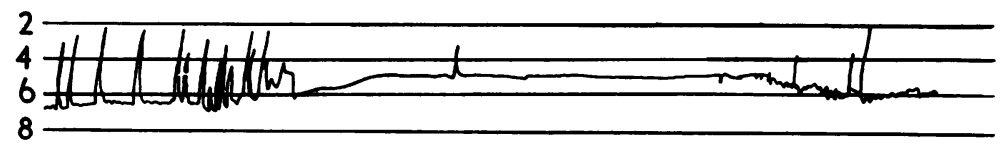

$\mathrm{pH}$

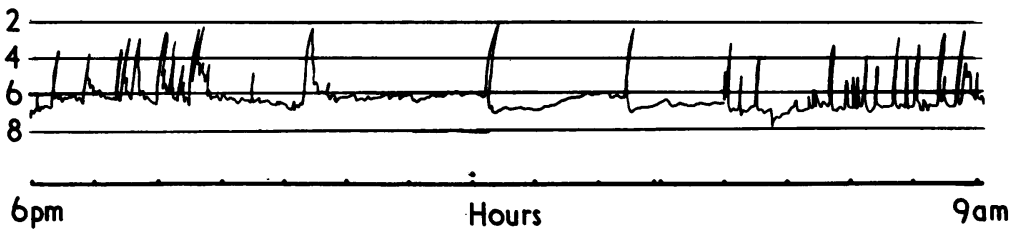

FIG. 2. Fifteen-hour records of oesophageal $\mathrm{pH}$ from two patients with normal oesophageal motility. Frequent reflux episodes are shown with rapid return of $\mathrm{pH}$ to neutrality on each occasion. In the nocturnal period, reflux episodes are much less frequent in both patients. In the upper record the slow fall in $\mathrm{pH}$ of $<2$ units occurred when the patient went to sleep, and the level of acidity reached was not sufficient for pepsin activation.

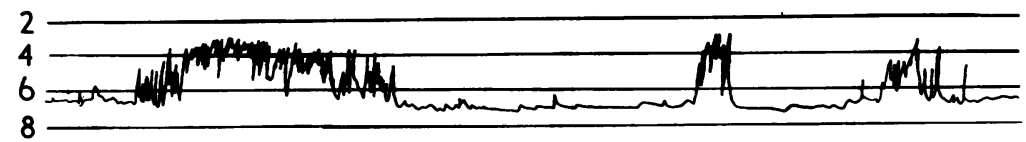

$\mathrm{pH}$

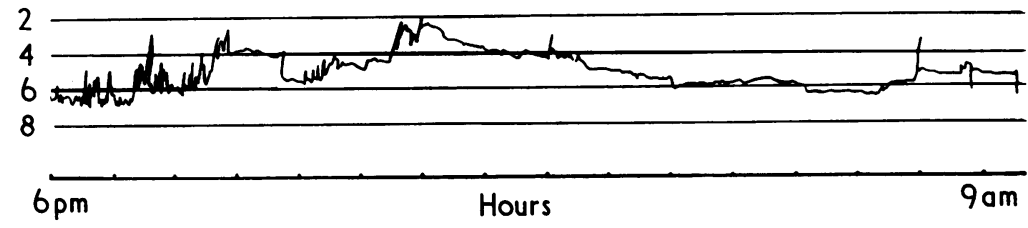

FIG. 3. Fifteen-hour records of oesophageal $\mathrm{pH}$ from two patients with abnormal oesophageal motility.

Upper: a patient with severe visual oesophagitis and motor failure.

Lower: No visual oesophagitis present. Manometric and radiological evidence of diffuse spasm.

In both patients prolonged periods of low $\mathrm{pH}$ are maintained, and there is no regular pattern of the clearance of acid from the gullet.

Thus the patients with normal motility tended to show a rapid return of $p H$ to neutrality after reflux, whereas though this feature was also present in patients with abnormal motility, they demonstrated consistently occasions when a low $p \mathrm{H}$ was maintained for a long period. The mean duration of these prolonged reflux episodes was 126 minutes with a range of 45 to 300 minutes. These features are demonstrated in Figures 2 and 3.
OESOPHAGEAL MOTILITY AND SEVERITY OF OESOPHAGITIS Of the 12 patients with abnormal oesophageal motility, 11 underwent oesophagoscopy. All $\stackrel{\circ}{+}$ 5 patients with marked inflammatory oesophagitis 0 showed abnormal oesophageal motility. However, $\vec{O}$ 6 patients with abnormal motility showed little or $\stackrel{\mathbb{\Phi}}{\rho}$ no evidence of oesophagitis.

Oesophagoscopy was performed on 11 of the 15 patients with normal oesophageal motility and oesophagitis was grade 0 in 8 and grade $A$ in 3. 


\section{DISCUSSION}

Many workers have used the $\mathrm{pH}$ electrode as a diagnostic and qualitative measure of the reflux of acid into the gullet in patients with hiatus hernia. With the electrode at diaphragmatic level Weber and Gregg (1959) found that normal patients demonstrated increased acidity in full expiration. For this reason in this study the electrode has been placed $5 \mathrm{~cm}$. above the candia. With an electrode at this level Tuttle, Rufin, and Bettarello (1961) defined reflux as occurring when the $p \mathrm{H}$ fell below 4 and, recording for a period of between 30 and 60 minutes, they found a good correlation between reflux and the sensation of heartburn. $p \mathrm{H}$ levels are only an index of acid concentration, but in this study, by recording over a long period and measuring the length of time under certain $p \mathrm{H}$ levels, we have obtained a quantitative index of gastro-oesophageal reflux for comparison with the patients' continuing symptoms.

In our patients with minor symptoms of reflux, $p \mathrm{H}$ did not fall below 4 for a significant period. Patients, however, with reflux to less than $p \mathrm{H} 4$ had variable symptoms, on the whole poorly related to the quantitative estimation of acid reflux. Symptoms at the time of the test were not a marked feature and not always associated with a reflux episode. The variability of reflux symptoms in patients with hiatus hernia obviously depends on whether or not gastric juice is entering the gullet, but our findings suggest that even when this occurs the patient's symptom response may be very variable. This unpredictable behaviour of patients with hiatus hernia is emphasized by Palmer (1968), who found that only $8.9 \%$ of 1,011 patients with hiatus hernia followed up for 20 years had classic symptoms of gastro-oesophageal reflux. Furthermore, only a quarter of his patients with visual oesophagitis had significant complaints. Skinner (1966) also reported a poor correlation between patients' symptoms and oesophagoscopic appearances. Our findings suggest that when electrode monitored reflux is slight, oesophagitis is usually mild or absent, but that when it is severe the degree of oesophagitis can be very variable.

In this study acid reflux has been recognized when a sudden drop of $p \mathrm{H}$ to 2 or more units below the basal level occurred, and the duration of a reflux episode as the time taken for $p \mathrm{H}$ to return to this level. The lowest $p \mathrm{H}$ reached depends on the concentration of hydrogen ions in the refluxed material, and the subsequent $p \mathrm{H}$ change is related to alteration in strength of the acid solution around the electrode produced by the buffering aotion of oesophageal secretion and swallowed saliva. Since mixing around the electrode is slow, the duration of a reflux episode probably depends primarily on bulk emptying of the oesophagus produced by contractile activity. It is likely that the reflux of small quantities of acid around the electrode produces a sharp fall in $p \mathrm{H}$ followed by an equally abrupt rise due solely to the buffering effect of oesophageal resting secretions. On the records this type of reflux episode has the appearance of a sharp spike without any width (Fig. 2). Examination of the results of Tuttle et al. (1961) supports this suggestion because rapid fluctuations in $p \mathrm{H}$ occur without any simultaneous manometric evidence of oesophageal contractions.

The clearance of larger amounts of gastric juice probably depends on secondary peristaltic activity induced by the refluxed bolus, as demonstrated by Creamer (1955). However, it is possible that this motor response is related to the volume refluxed because Nagler and Spiro (1961) found that secondary peristalsis occurred only in patients in whom relatively large volumes could be aspirated from the gullet after reflux induced by abdominal compression. This is important because it suggests that peristaltic activity might not remove small amounts of refluxed gastric juice from the oesophagus. Our records, however, fail to demonstrate slow falls of $p \mathrm{H}$ which might be expected to occur if small amounts of gastric juice oozed past an incompetent cardia at night, as suggested by Aylwin (1953). In several patients a slow fall of less than $2 \mathrm{pH}$ units occurred during sleep, but the range of peptic activity was not reached. It was felt that this slight fall of $p H$ during sleep was due to the decreased amount of swallowed saliva rather than to reflux of acid gastric juice (Fig. 2).

Creamer (1955) suggested, in patients with the symptoms of oesophagitis, that the secondary peristaltic response following reflux was sometimes inco-ordinated, and Donner and his associates (1966), studying similar patients radiologically, found that swallowed acid barium was cleared abnormally slowly from the gullet because of the presence of motor abnormalities in the lower oesophagus.

The clearance of refluxed acid must also depend on primary peristaltic activity produced by a swallow. Tuttle (Tuttle and Grossman, 1958 ; 
Tuttle, Bettarello, and Grossman, 1960) states that dry swallows have little effect on an acid $p \mathrm{H}$ existing in the lower oesophagus, and even wet swallows have only a transitory effect lasting 5 to 30 seconds. However, since their patients were examined in the supine position, prolonged low $p \mathrm{H}$ levels may have been due to reflux following relaxation in the lower oesophageal intrinsic sphincter produced by swallowing. The work of Booth et al. (1968) more specifically suggests that the efficiency of the primary peristaltic wave may be at fault in hiatus hernia patients with the symptoms of oesophagitis because they required more voluntary swallows to raise oesophageal $p \mathrm{H}$ to normal following the experimental instillation of hydrochloric acid than did asymptomatic hiatus hernia patients or normals.

Thus altered primary and secondary peristaltic activity may be responsible for delayed clearance of acid in symptomatic patients. Our results suggest that delayed clearance of acid is much commoner in patients with abnormal oesophageal motility. The relationship of delayed clearance of acid to symptoms is, however, less clear since 2 of our 12 patients with abnormal motility and slow acid clearance had no symptoms and 4 only minor symptoms of gastro-oesophageal reflux. In the patients with abnormal motility the severity of symptoms did not appear to have any relationship to the degree of oesophagitis, though the numbers are too small to be of any significance.

It has been suggested (Ingelfinger, 1963 ; Tuttle et al., 1961) that for the symptoms of gastro-oesophageal reflux to occur a 'fertile soil' must be prepared. The absence of symptoms in many of our patients with demonstrable acid reflux, and particularly the presence of prolonged reflux in patients with abnormal motility suggests that the latter may allow sufficient exposure of the gullet to refluxed acid to cause damage to the mucosa and the subsequent development of symptoms.

All of our patients with severe visual oesophagitis displayed abnormal oesophageal motor function, and this finding agrees with those of Olsen and Schlegel (1965). However, their suggestion that abnormal oesophageal motility is secondary to the oesophagitis is not completely supported by our findings, because over half of our patients with abnormal motility had absent or minor oesophagitis. This finding would support the suggestion that abnormal motor function in some patients may be the initiating factor allowing refluxed acid to remain in the oesophagus long enough to produce inflammatory oesophagitis.

\section{CONCLUSIONS}

A history of significant symptoms of reflux was usually associated with the occurrence, for a measurable time, of oesophageal acid levels of less than $p \mathrm{H}$ 4. However, $p \mathrm{H}$ levels of less than 4 could occur in the absence of a history of symptoms of acid reflux, and there was a poor correlation between symptoms and measured acid levels at less than $p \mathrm{H} 4$.

Normal oesophageal motility was associated with rapid clearance of refluxed acid from the gullet. Long periods of low $p \mathrm{H}$ after reflux occurred in patients with abnormal oesophageal motility, suggesting that bulk removal of refluxed acid was impaired in this group.

Such delayed acid clearance was associated with the presence of oesophagitis, but, although there was a correlation between these two, they were not together as a group related to the symptomatic state of the patients.

It is suggested that in some patients with hiatus hernia and reflux abnormal motor function of the oesophagus may predispose to the development of inflammatory oesophagitis because of delayed clearance of refluxed gastric juice.

I am grateful to Mr. J. Leigh Collis for his advice and for providing the facilities to study patients under his care.

This work was supported by grants from the Birmingham Regional Hospital Board and the Endowment Fund of the United Birmingham Hospitals.

\section{REFERENCES}

Aylwin, J. A. (1953). The physiological basis of reflux oesophagitis in sliding hiatal diaphragmatic hernia. Thorax, 8, 38 .

Booth, D. J., Kemmerer, W. T., and Skinner, D. B. (1968). Acid clearing from the distal esophagus. Arch. Surg., 96, 731.

Creamer, B. (1955). Oesophageal reflux. Lancet, 1, 279.

Donner, M. W., Silbiger, M. L., Hookman, P., and Hendrix, T. R. D (1966). Acid-barium swallows in the radiographic evaluation of clinical esophagitis. Radiology, 87, 220.

Ingelfinger, F. J. (1963). The esophagus, March 1961 to February $\mathrm{N}$ 1963. Gastroenterology, 45, 241.

Nagler, R., and Spiro, H. M. (1961). Heartburn in late pregnancy. N Manometric studies of esophageal motor function. J. clin. Invest., 40, 954

Olsen, A. M., and Schlegel, J. F. (1965). Motility disturbances caused $\sigma$ by esophagitis. J. thorac. cardiovasc. Surg., 50, 607.

Palmer, E. D. (1968). The hiatus hernia-esophagitis-esophageal 0 stricture complex. Amer. J. Med., 44, 566.

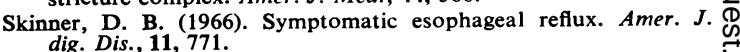

Tuttle, S. G., Bettarello, A., and Grossman, M. I. (1960). Esophageal acid perfusion test and a gastroesophageal reflux test in patients with esophagitis. Gastroenterology, 38, 861.

- and Grossman, M. I. (1958). Detection of gastroesophageal $\vec{D}$ reflux by simultaneous measurement of intraluminal pressure $\Omega$ and pH. Proc. Soc. exp. Biol. (N.Y.), 98, 225.

Rufin, F., and Bettarello, A. (1961). The physiology of heartburn. Ann. intern. Med., 55, 292.

Weber, J. M., and Gregg, L. A. (1959). pH in situ of esophageal and gastric contents, with particular reference to hiatal hernia. Gastroenterology, 37, 60 . 